\title{
Mathematical imagination and embodied cognition
}

\author{
Ricardo Nemirovsky • Francesca Ferrara
}

Published online: 19 September 2008

(C) Springer Science + Business Media B.V. 2008

\begin{abstract}
The goal of this paper is to explore qualities of mathematical imagination in light of a classroom episode. It is based on the analysis of a classroom interaction in a high school Algebra class. We examine a sequence of nine utterances enacted by one of the students whom we call Carlene. Through these utterances Carlene illustrates, in our view, two phenomena: (1) juxtaposing displacements, and (2) articulating necessary cases. The discussion elaborates on the significance of these phenomena and draws relationships with the perspectives of embodied cognition and intersubjectivity.
\end{abstract}

Keywords Mathematical imagination · Embodied cognition · Gesture ·

Tool use $\cdot$ Trigonometry

\section{Mathematical imagination}

We view mathematics learning as the development of a particular type of imagination, which we call "mathematical imagination". This paper is a preliminary analysis of some aspects of the mathematical imagination in light of a 17-second episode that took place in a 10th-grade high school mathematics classroom. The analysis of the classroom episode centers on the gestures and words of a student as she explains the necessity of a particular orientation for a triangle.

Imagining, we propose, is entertaining possibilities for action; entertaining (in the sense of "holding" or "keeping") a state of readiness for the enactment of possible actions. A key point

R. Nemirovsky $(\bowtie)$

Department of Mathematics and Statistics, San Diego State University, 5500 Campanile Drive, GMCS Building, Room 503, San Diego, CA 92182-7720, USA

e-mail: nemirovsky@sciences.sdsu.edu

R. Nemirovsky

Center for Research in Mathematics and Science Education (CRMSE),

6475 Alvarado Rd. Suite 206, San Diego, CA 92120-5013, USA

F. Ferrara

Dipartimento di Matematica, Università di Torino, Turin, Italy 
is that the activity of imagining is fully part of any perceptual and motor activity. We perceive, say, an approaching car, in entirely different ways if we hold the possibility of being hit by it or not. Similarly, we proceed to grab an object in entirely different ways depending on the possible weights that we entertain for it. To highlight this intrinsic unity we will talk about perceptuo-motor-imaginary activity. Ferrara (2006) has analyzed the role of imagining in mathematics learning as central to the perceptual and motor activity of the learners.

A distinction that we deem of great importance was introduced by Husserl (1983) and elaborated by Casey (1979): the distinction between empirical and pure possibilities. Empirical possibilities are those that we hold on the basis of empirical observations. To mention Casey's example, on the basis of empirical evidence (e.g. the appearance of the sky, weather reports, what has happened the day before, etc.) we act to pick up an umbrella or leave it at home, before going outside. Pure possibilities, on the other hand, are immune to empirical evidence: we hold them as a result of our positing them unconditionally. Typical instances of pure possibilities are offered by literary fiction. No historical document will ever show that Alice, the one who traveled in Wonderland, had a younger brother, or that, in fact, Don Quixote died when he was 69 years old. Obviously countless instances of literary fiction are hybrids that combine empirical and pure possibilities. But this hybridization does not take away the fact that we customarily distinguish between them (e.g. historical and fictional sites of Dickens' portrayals of London). Note that by "pure possibilities" we do not mean Platonic ideals; possibilities are "pure" because of how we experience them (i.e. we bring ourselves into a readiness for them regardless of their empirical likelihood).

Like literary fiction, mathematical imagination entertains pure possibilities. However, numerous traits distinguish them. The one that we want to emphasize here is that the possibilities held by mathematical imagination are regulated by, or embedded in, a sense of logical necessity in all its deductive and inductive modalities. Cervantes tells us that the birth name of Don Quixote was Alonso Quijano, but it is not the case that it had to be Alonso Quijano: Cervantes could have fancied countless other possible birth names. In mathematics many decisions are equally arbitrary, but some of them seem forced by their premises to be what they necessarily are. This contrast between literary fiction and mathematics does not imply that the former lacks coherence or "logic" in the colloquial sense. The distinguishing trait we are trying to point out is that for an author writing literary fiction no outcome is strictly impossible: she excludes possibilities because they would make bad fiction, not because they could not be accommodated in principle. The sense of logical necessity pervading mathematics is common in the play of rule-based games (i.e. unless players violate rules, certain moves are strictly impossible). Let us examine an elementary example of how logical necessity often overrides empirical appearances. Suppose that we draw a staircase, such that the height of each step is the previous one plus a constant length, and the length of each horizontal segment is equal to the previous vertical one (see Fig. 1).

After a few steps we easily notice, visually, that the vertices of each step appear to be such that they could be joined by a straight line. However, we know that the ratio between the vertical and the horizontal segments of each step is different from the previous one or the following one; "therefore", it "cannot be" that a single straight line touches more than two successive vertices. Such logical necessity transforms the visual recognition of a straight line touching successive corners into a mere appearance.

Pure possibilities entail symbol-use: perceptuo-motor-imaginary activity with symbols. Symbol-use is part of what makes pure possibilities immune to empirical evidence. We know about the conversation between Alice and the Queen because we read it in the book, not because we have actually heard what they said. Analogously, we prove properties of 
Fig. 1 Staircase in which the height of each step is the previous one plus a constant length, and the length of each horizontal segment is equal to the previous vertical one

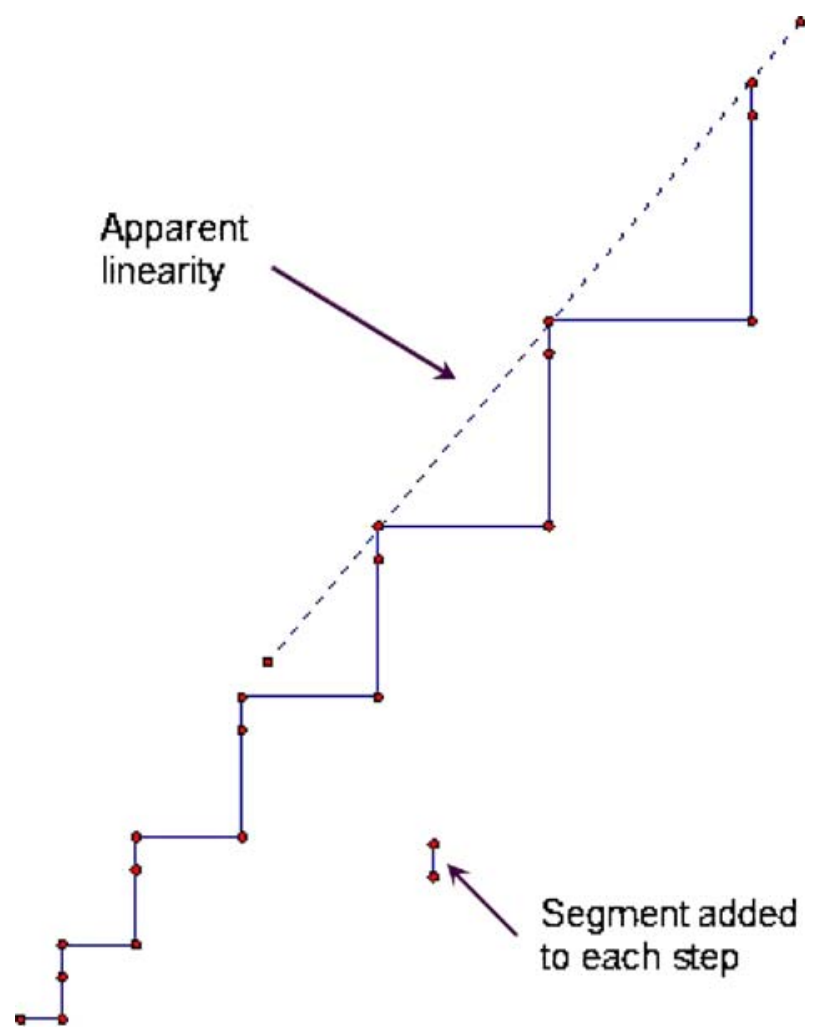

mathematical entities through symbolizing them, not by observing them as such. Analogously to the case of literature, many mathematical conversations are hybrids encompassing empirical and pure possibilities, but the difference between them often becomes conspicuous to the participants in the course of analysis or disagreements.

\section{Embodied cognition}

Mathematical understanding has been studied from perspectives informed by embodied cognition (Lakoff and Núñez 2000). Many views have been developed on embodied cognition. The one that we tend to adopt is well described by Gallese and Lakoff (2005):

We will argue that conceptual knowledge is embodied, that is, it is mapped within our sensory-motor system. We will argue that the sensory-motor system not only provides structure to conceptual content, but also characterises the semantic content of concepts in terms of the way that we function with our bodies in the world (pp. 455-456).

From this perspective, embodied cognition rejects the notion that behind perceptuomotor activity there is a "mind", suffused with formal propositions and inferential rules, that drives the former. Whatever we can recognize as rational, rule-based, or inferential, is fully embedded in our bodily actions; perception and motor activity do not function as input and output for the "mental" realm; what we usually recognize as mental are inhibited and condensed perceptuo-motor activities that do not reach the periphery of our nervous system. 
We find Gallese and Lakoff's characterization of embodied cognition illuminating, but also lacking an aspect crucial to our analysis: that what they call the "sensory-motor system" must prominently include imaginary activity (Johnson 1987), which is the reason we prefer to call it perceptuo-motor-imaginary activity. Any perceptuo-motor activity is inscribed in a realm of possibilities encompassing all those for which the subject achieves a certain state of readiness. In this sense all animals imagine, not just humans, although it is not clear to what extent non-human animals entertain pure possibilities.

\section{Utterance and thought}

To explicate the research methodology, we will use the term "utterance" to encompass all types of body activity that play a part in a given conversational turn or transaction. This definition suggests a use of "utterance" that includes multimodal aspects such as: facial expression, gesture, tone of voice, sound production, eye motion, body poise, gaze, and so forth (see Fig. 2).

Multimodality is an important aspect of current work on research in mathematics education (Arzarello 2006) and of emerging perspectives on embodied cognition:

Multimodal integration has been found in many different locations in the brain, and we believe that it is the norm [...]. That is, sensory modalities like vision, touch, hearing, and so on are actually integrated with each other and with motor control and planning. This suggests that there are no pure "association areas" whose only job is to link supposedly separate brain areas (or "modules") for distinct sensory modalities.

(Gallese and Lakoff 2005; p. 459)

Research on learning is devoting increasing attention to the study of utterances in the multimodal sense described above, with a particular emphasis on gestures (Robutti 2006; Roth and Welzel 2001; Sabena 2007). Radford has developed a perspective in which mathematical semiotic spaces are constituted and navigated through utterances (Radford 2006; Radford, Bardini, Sabena, Diallo and Simbagoye 2005).

Through interaction with others, utterances become collective or group-phenomena. They often get "orchestrated" as in a joint choreographic production (for a study that includes analysis of utterances as group activities see Sabena 2007; for a more general treatment see Erickson 2004). Speakers incorporate objects and physical tools into their utterances, in which case these objects and tools become fully partakers of the utterance itself.

Any utterance involves both overt and covert aspects (see Fig. 3). Overt aspects are those that reach the periphery of the nervous system and become physically noticeable for an observer, whereas covert aspects are those inhibited by the speaker so that their activity remains largely within the central areas of the nervous system. The covert aspects of utterances constitute what in everyday life we call "mental". In our interpretation, the point embodied cognition strives to advance is not that mental phenomena do not exist, but that

Fig. 2 Multimodality of an utterance

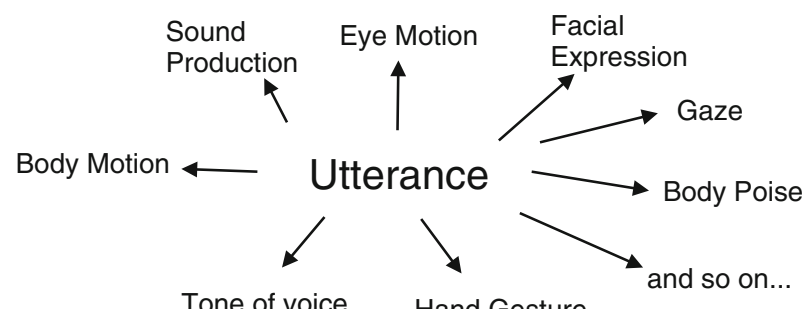

Tone of voice

Hand Gesture 
Fig. 3 Overt and covert aspects of an utterance

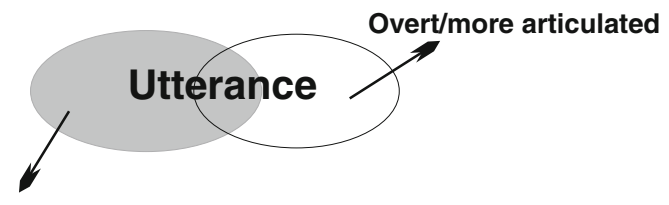

Covert/Inhibited/more condensed

there is no difference "in kind" between mental and behavioral action. Rather, differences between the inhibited (i.e. mental) aspects of an utterance and the overt ones tend to be that the former ones are enacted in a "condensed" manner: condensed in a sense related to the one used by Vygotsky to describe inner speech (Vygotsky 1986). For example, when we covertly articulate the name of someone (i.e. think his name) we just become ready to articulate his name and go on into whatever follows, without completing it. This readiness is commonly achieved by enacting a configuration of sound production corresponding to the first letter or phoneme; this might explain why it is frequent that when one forgets a name one still recalls its first letter: the first letter is more often (covertly) practiced than the whole name.

Given this use of "utterance", we propose to conceive of "thoughts" as interpretations of the speaker's utterances. In everyday life we are constantly interpreting utterances to grasp what the speaker "thinks". To grasp a thought that seems to animate an utterance, we need to develop a sense of who the speaker is, what issue (s)he is trying to address, whom (s)he is talking to, where (s)he is, and so forth. Even if we were able to know the state of each neuron of a speaker over time, such knowing would not be enough to take hold of her/his thoughts. We would also need to capture the context, the aims, the immediate past, etc., that is, all aspects which are not necessarily to be found inscribed in neuronal networks but in the lived context/culture and surroundings of the speakers. From this perspective, thoughts are not entities to be reified with causal powers. Utterances are the substance of our experience, the thoughts that account for them are, like any interpretation, open ended and subject to revision in light of alternative points of view.

The research question we pursue in the present paper is the following one: What qualities of mathematical imagination we do identify in light of the selected classroom exchange?

\section{The study and the classroom}

The teaching experiment took place in a 10th-11th grade algebra class taught by Apolinario Barros to students of varying ages from Cape Verde. The class was part of a bilingual program within Boston Public Schools for recent immigrants from Cape Verde. The 21 students, as well as the teacher, were all Capeverdians residing in Boston. The research team included the first author, Apolinario Barros, Tracy Noble, Cara diMattia, and Teresa Lara-Meloy. The second author of this paper participated in the subsequent analysis of these classroom sessions. The students' talk mixed Capeverdean and English. The episode we will discuss in this paper took place on May 5th 2002, during the second of a sequence of seven sessions which overall took place over a 2-week period. All the sessions were videotaped with two cameras and transcribed by a native Capeverdean speaker who also translated it to English.

The teaching experiment was designed for the learning of concepts of trigonometry involving body motion and technologies designed to integrate kinesthesia and mathematics learning. Throughout the sessions the students used different devices. The device that is relevant to the episode selected for this paper is the one we called "Pointer Device". The 
Fig. 4 The pointer device

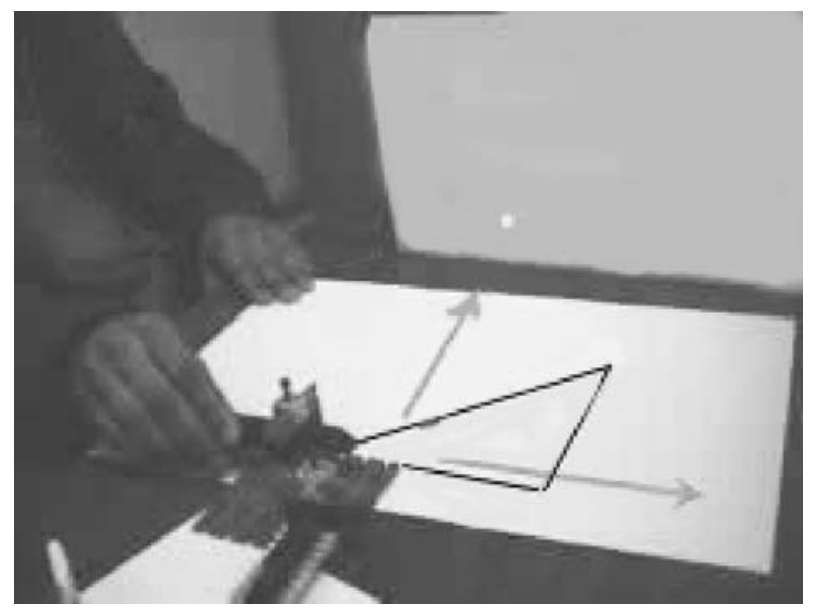

device consists of two laser pointers held up at $90^{\circ}$ from each other (see Fig. 4). The laser lights reflect on two side panels set up along perpendicular axes (see vertical panel on the left side of the student in Fig. 4 along one of the axes). The idea is to move the device tracing a certain figure (for instance a triangle, shown with black lines in Fig. 4) while keeping the orientation of the laser pointers always perpendicular to the side panels on which their light shines. In this way, the points of light shining on the two panels reflect a parametric decomposition, say along $X$ and $Y$ axes, for the path of the traced figure. In other words, each point traced on the flat figure (e.g. the triangle shown in Fig. 4) gets decomposed in $X$ and $Y$ coordinates made visible by the laser lights on the two side panels. The students worked in teams of three, each with a laser pointer device and an open folder standing vertical for the $X Y$ side panels. They studied the correspondence between the lines traced on the flat sheet of paper and the trajectory of the two laser lights on the side panels.

After the students had worked with the pointer device and discussed their observations, Tracy Noble stood behind large side panels (see Fig. 5), and traced, in front of the whole class, a triangle shown in Fig. 6.

Fig. 5 Classroom arrangement

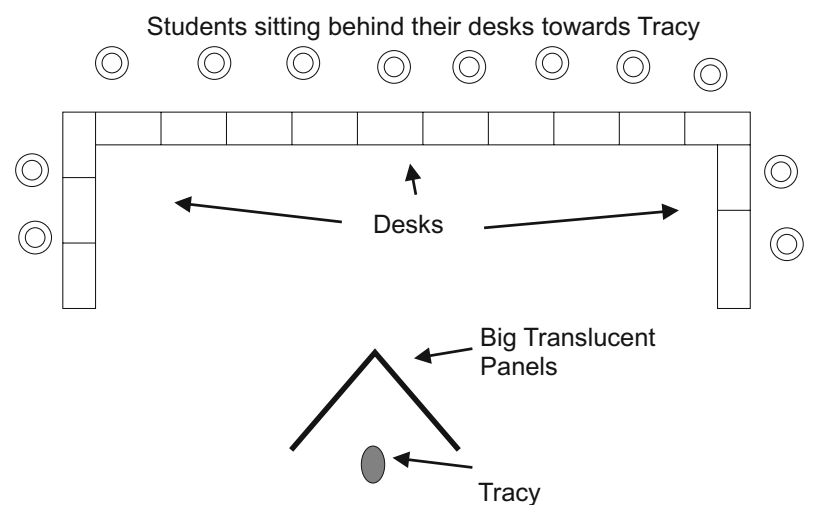


Fig. 6 The triangle that Tracy traced in front of the class, with the Pointer Device behind translucent panels

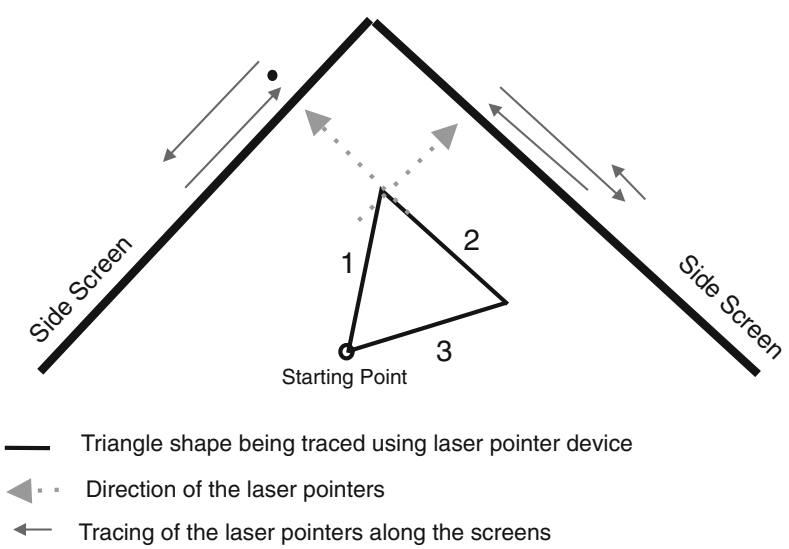

The class was able to see only the movement of the points of light shining through the translucent panels; in other words, the class did not see which figure Tracy was tracing but the moving points of light she generated with the laser pointer device on the two side panels. The ensuing class discussion was about the sort of triangle that corresponded to the motion of the lights they had seen. As can be seen from Fig. 6, the triangle had been an equilateral one oriented in such a way that the tracing of the first side (labeled ' 1 ' in Fig. 6) corresponded to both lights moving toward the vertex of the side panels, the second side left one light still and moved the other one away from the vertex, and the tracing of the third side of the triangle moved one light toward the vertex and the other one away from it. The students discussed several ideas, such as that the triangle had only one side parallel to the $X Y$ panels: the one whose trace had left one of the lights still.

\section{Carlene}

The class discussion on the triangle traced by Tracy lasted for 4 min and $45 \mathrm{~s}$. The last student who participated in this discussion was Carlene. She talked during the $45 \mathrm{~s}$ interval enacting 26 distinct utterances. Given the space available for this paper, we analyze the final sequence of nine utterances which took $17 \mathrm{~s}$. Before these nine utterances Carlene spoke in English; she switched to Capeverdean at the beginning of the sequence discussed here. We will examine in these utterances two phenomena that we call "juxtaposing displacements" and "articulating necessary cases". By describing and illustrating them embedded in Carlene's utterances, we address our research question: What qualities of mathematical imagination do we identify in light of the selected classroom exchange?

"Juxtaposing displacements" describes imagining as enacting partial aspects of a situation-each taking place in distinct times and locations - next to each other (i.e. juxtaposed). Aspects which in the imagined situation are simultaneous or contiguous are enacted sequentially or apart from each other, and vice versa. To use a simile: imagining is not so much bringing things/events into place as in a perspective painting, but as in a cubist painting where different planes, angles, and times are brought next to each other in a composition whose overall aim is to illuminate a specific way of grasping a whole which is extended in space and time. For this reason we will use indistinguishably "juxtaposing displacements" and "cubist composition". This phenomenon is not unique to mathematical 
imagination and it might very well be a general trait of imagination. We propose that cubist composition is also present in mathematical imagination and we will illustrate a particular occurrence in this classroom episode.

"Articulating necessary cases" refers to the split of the imagined phenomena-with all its potential complexity susceptible to be partitioned in infinite ways - in separate, necessary cases articulated on the basis of principles or rules that appear to be obviously true. This is a phenomenon that is more restricted to mathematical imagination, although it is not exclusively mathematical (e.g. rule-based games are often described by articulating necessary cases).

\section{Juxtaposing displacements}

Before Utterance 1 (Fig. 7), Carlene explained in English how she imagined the triangle on the basis of how the lights had moved on the panels. Carlene's talk had been full of pauses expressing her struggle with English as a second language. Sensing that she was not being understood, she switched to Capeverdian. Now, talking fluently, she directed herself to Apolinario Barros expecting that he would translate her ideas into English, so that Tracy could understand her. Utterance 1 is the beginning of her explanation. Utterance 1 amounted to placing imaginary $X Y$ side panels in front of her. The orientation of the panels with respect to Carlene replicated the orientation that the big panels in front of the class had with respect to Tracy: Carlene was standing symmetrically in between and behind them (see Fig. 8).

In Utterance 2 (Fig. 7) Carlene re-positioned the imaginary panels for them to coincide with the edges of her desk, so that her index fingers, "touching" the position of each light, moved along these edges. The physicality of the desk's edges facilitated the marking of the lights' movement for Carlene: it made their path more salient and better defined. In terms of Hutchins' (2005) analysis, the edges of the desk functioned as opportunistic "material anchors" that helped Carlene stabilize the events she imagined. Noble (2007) analyzed how material anchors generate sensory-motor feedback for the user, offering a kind of feedback that participates in the thinking itself. In this case, the edges of the desk might have guided her fingers, in a perceptuo-motor sense, as Carlene traced the motion of the laser lights, letting her feel that the lights followed a clearly defined linear path.

Utterance 1

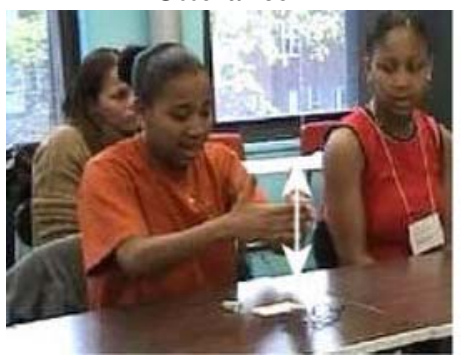

Kel kuza e assi

that thing is like this
Utterance 2

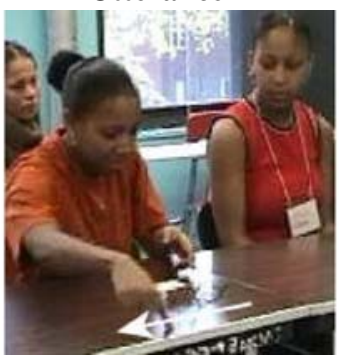

kela taba pra ote

that one moves that way,

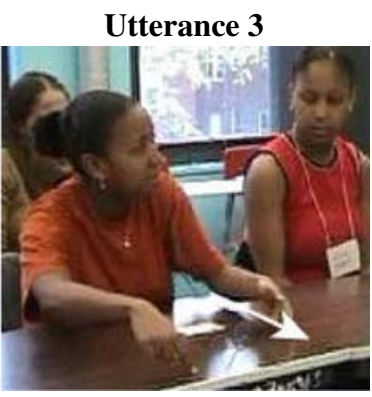

ta ben pra li. (...)

this one moves this way.(...)

Fig. 7 Utterances 1-3 
Fig. 8 Relative positions between Carlene and Tracy
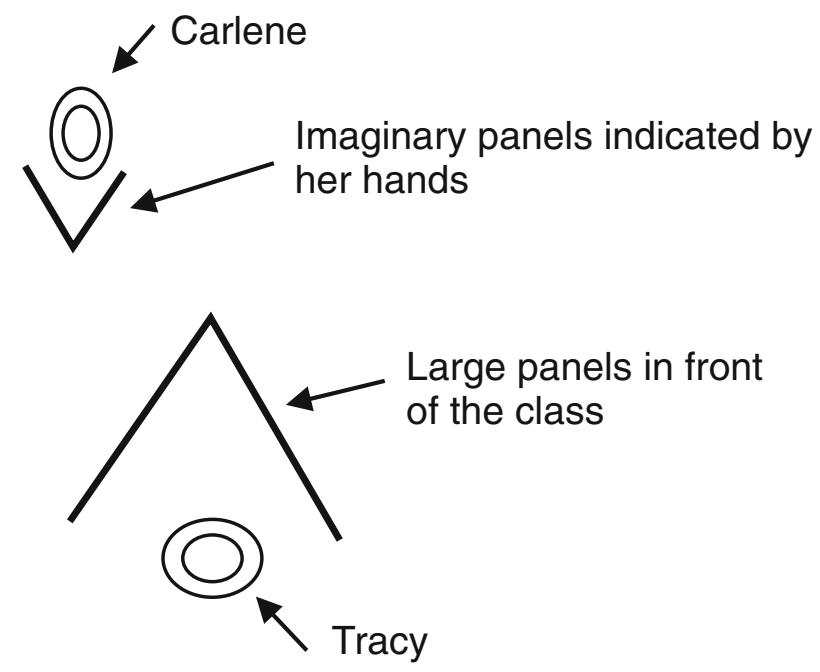

The motions of the laser light Carlene referred to in Utterances 2 and 3 (Fig. 7) were similar to the ones generated by side ' 3 ' of the triangle traced by Tracy in front of the class, as seen from her position (see Fig. 6). In other words, Carlene moved both lights from her left side to her right side, which is how she, and the rest of the students, had seen the lights moving when side ' 3 ' had been traced (Fig. 6). In Utterances 1 and 2 Carlene looks at her own desk as if watching the motion of the lights from left to right, as she had seen them moving on the large panels in front of the class. In Utterance 3 she lifts her gaze toward Apolinario Barros, to whom she is directing her talk.

In these initial utterances we notice three displacements in space: (1) she mirror-reflected the side panels located in front of the class and placed them in front of her, (2) she then rotated the side panels to coincide with the edges of her table, and then (3) she translated the motions of the lights generated by Tracy for side ' 3 ' of the triangle (Fig. 6), inverting the right/ left orientation they had had from Tracy's point of view. We can also notice a fourth temporal displacement: (4) while the motion of the lights indicated in Utterances 2 and 3 had been simultaneous, her hands and talk showed them sequentially, one after another. In Utterance 3, as her left hand traced the movement on the left edge of her table, her right hand stayed still at the end of its corresponding motion, as if "holding" its past motion while generating the new one with the other hand. All these displacements were juxtaposed by her own gesturing and talk, in the sense that they occurred contiguously in the same "peripersonal" space (i.e. the space of eye-hand coordination, encompassing the region of what is graspable by an acting body) demarcated by her desk and in the continuity of her lived time. Carlene's bodily activity was not enacting the imagined events as a full consistent replica of their occurrence. Rather, she brought together glimpses of the imaginary events combining different spatial and temporal perspectives. The intentionality of her actions was not a "realistic" enactment, but the highlighting of distinct aspects brought together in the unitary framework of her lived space-time.

Juxtaposing displacements is likely to be pervasive in imaginary activity; this leads us to suggest that imagining resembles the creation of cubist paintings, rather than paintings organized in terms of an overall point of view structured by the techniques of linear perspective. Rather than animating scenes from a single point of view, such as an unedited regular photo shoot does, the imaginary activity appears to jump from one point of view to 
another, making the simultaneous sequential, and altering the temporal order of events. The unity of all these glimpses - the unity lived by the imaginer and her listeners - emanates from their ongoing juxtaposition in the imaginers' lived space and time.

\section{Articulating necessary cases}

In Utterances 4 and 5 (Fig. 9) Carlene elaborates on the case in which one traces a line oriented toward the vertex of the side panels, in which case the two moving points on the side panels move toward their intersection. In Utterance 4 her left arm rests on the left edge of the table - an edge holding one of the side panels - while her left index finger points at the vertex, which is the point aimed by the right hand moving along a bisecting line. Note that her whole right hand stresses directionality and aim of the motion, which is something that changes in Utterance 5: now her hands contract, letting the index fingers indicate the position of the points of light moving on the side panels. Carlene looks at her moving hands, the right one in Utterance 4 and both hands approaching the vertex in Utterance 5. Listeners usually fix their gaze on the face of the speaker, except when the speaker looks at something away from the listeners themselves. Carlene's look at her moving hands might have been a way of emphasizing for herself and for her listeners, the most critical aspects of her utterances.

In Utterances 6-8 (Fig. 10) Carlene illustrates a second case. Now the line is oriented "backwards". Her left arm is again marking one of the side panels, as in Utterance 4, but now the right hand aims at her elbow. Instead of approaching the vertex located in the "forward" extreme of the table, it approaches the opposite side which is "backward" with respect to her. Her right hand is extended to stress this backward directionality for the imaginary line. She then extends her index fingers to indicate the corresponding motion of the laser lights, breaking their temporal simultaneity in a sequence similar to Utterances 2 and 3. In Utterance 7 Carlene makes apparent the intricate and multilayered aspects of hand motion: she describes the movement as "up" ("pa riba"), which reflects the natural motion of the arm forward (i.e. as we move the hand away from us in the forward direction we tend to move it up also).

The class had differentiated three cases for the motion of the laser lights corresponding to the three sides of the triangle traced by Tracy. Carlene articulated two of them corresponding to the sides ' 1 ' and ' 3 ' of the triangle used by Tracy (see Fig. 6). Side 2 was an "obvious" case because it was well established by the class that if one of the lights

Fig. 9 Utterances 4 and 5

Utterance 4

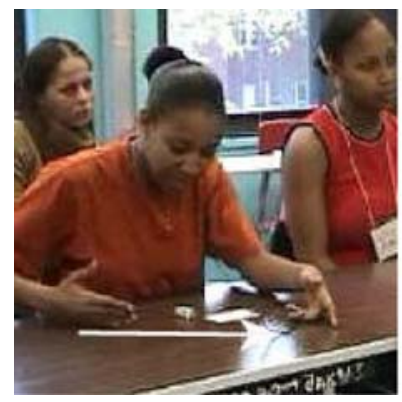

Y konde bo ta faze-1 linha reta

And when you make a straight line
Utterance 5

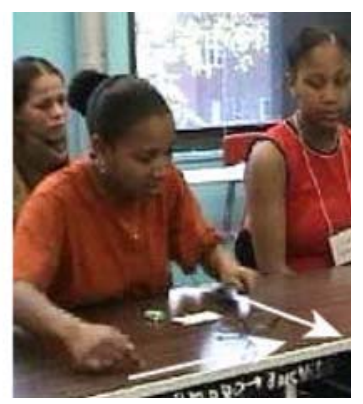

es ta ben assi.

it moves like this. 


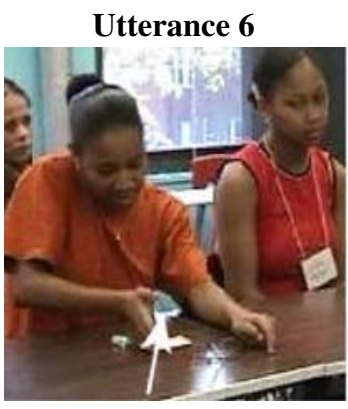

Konde bo ta faze-1 pa trás (..)

When you move backwards

(..)

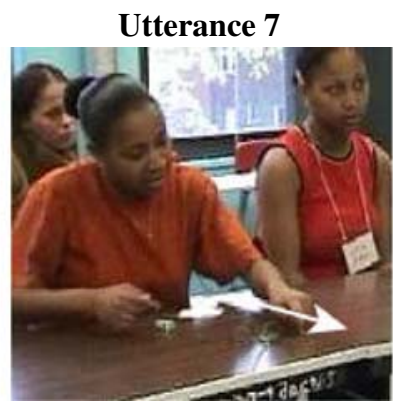

kela ta ba pa riba that one moves up,

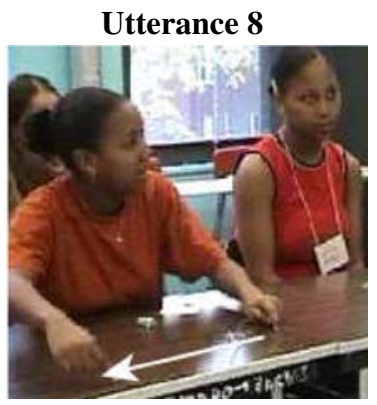

kel ote ta ben pra li. the other one moves this way.

Fig. 10 Utterances $6-8$

remained still, the Pointer Device could only move parallel to one of the side panels. Carlene articulated the cases of sides ' 1 ' and ' 3 ', each on the basis of a rule or principle:

- Case '1': A movement toward the center ('forward') makes the two lights converge toward the vertex of the panel;

- Case '3': A movement away from the center ('backward') makes one light converge toward the vertex of the panel and another diverge from it.

Carlene did not articulate these rules in terms of self-contained statements. They were rather embedded in the flow of her words, gestures, facial expressions, tones of voice, and so forth. Notice Carlene's choice for the two motions illustrated by her right hand (Utterances 4 and 6). The reader surely realizes that in principle there can be infinite configurations generated by the Laser Pointer and the motion of its lights, and that for any pair of them there are continuous variations that will go from one to the other. However, a key aspect for the constitution of logical necessity is the split of necessary cases which are often marked, as it was by Carlene, by "extreme" instances that avoid borderline possibilities. The bare duality forward/backward of Carlene's line-tracing (Utterances 4 and 6) appears to impose relative motions of the lights that are distinct and necessary. By means of her words and gestures Carlene articulated the two non-obvious cases in terms of rules that appeared true and necessary. The movement of the laser lights generated by Tracy had to be generated by a triangle that had one side parallel to a panel (when one of the lights remained still), another side that was traced toward the vertex (Utterance 4, when both lights moved toward the center), and another side that was traced "backwards" (Utterance 6, when the lights had moved toward and away from the vertex).

The motions of the lights Carlene showed in Utterances 7 and 8 are opposite to the ones that would correspond to the Pointer Device moving in the "backward" direction she indicated in Utterance 6. Utterances 6-8 juxtaposed a replica of the motion Tracy had effected for side ' 3 ' - Carlene moved her hand as if she were in the back of the panel, as Tracy had been - with the corresponding motion of the lights as Carlene had seen them from the back of her own table. It is likely that Carlene was unaware of this mirror reflection for the motion of the Pointer Device or the lights' motion. We suggest that these type of inconsistencies are fully part of articulating necessary cases. When we articulate necessary cases the aim is not to remove every possible ambiguity; on the contrary, the 
ambiguity of the exact direction backward (Utterance 6) and forward (Utterance 4) for instance, is a key to the fact that she was imagining a range of possible movements and not just the exact one that she enacted with her right hand in these utterances. This is also true of juxtaposing the line-tracing (Utterance 6) with the motion of the lights (Utterances 7-8) which were mirror-reflected with respect to each other. What Carlene wanted to oppose were the case in which both laser lights move in convergence to the vertex vs. the case in which they do not, as it had been with the sides ' 1 ' and ' 3 ' of the triangle in Fig. 6. This opposition holds regardless of whether the lights move from left to right or from right to left in the case portrayed by Utterance 6 .

In Utterance 9 (Fig. 11) Apolinario Barros voiced Carlene's conclusion in English. As he said "in the same direction" (underlined in the text of Utterance 9), Carlene, looking at him, moved her hands toward each other at least twice (the camera pans away at this time) and smiled while assenting with her head. Carlene was pleased to see that the teacher had grasped the essence of her idea. Mr. Barros described two opposite cases that seemed to reveal, with the force of necessity, the nature of the triangle that had been traced behind the translucent panels.

\section{Discussion}

In Section 6, we analyzed three utterances in which Carlene enacted juxtaposed displacements (See Fig. 12). First she mirror-reflected the side panels, then she anchored the side panels on the edges of her table, a third displacement was the translation of each of the lights' movements preserving the left/right orientation they had had from her point of view; the fourth displacement was temporal: enacting two simultaneous motions in sequence $(\mathrm{U} 2) \rightarrow(\mathrm{U} 3)$.

Fig. 11 Utterance 9

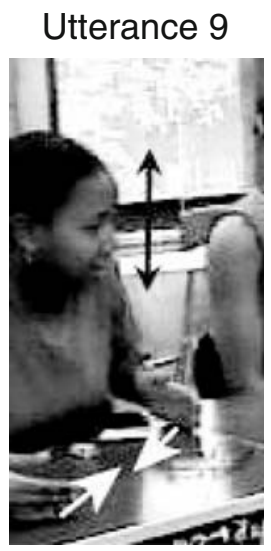

Mr. Barros: Oh, OK. So one time they go in the same direction. And another time they go in the opposite direction 
We wanted to illustrate through this example the phenomenon of cubist compositions (juxtaposing displacements): mathematical imagining (and possibly imagining in general) entails juxtaposing distinct and fragmentary (i.e. displaced) viewpoints and moments. Such "collage" of viewpoints and moments unfolds as a novel composition in the lived space and time of the imaginer and her listeners. The aim of these compositions, authored in the selected episode by Carlene, was to convey her overall point regarding the orientation of the triangle Tracy had followed with the laser pointer device.

In Section 7 we discussed Utterances 4-9. Carlene juxtaposed numerous displacements in these utterances, but our analysis focused on her "articulating" of two necessary cases (see Fig. 13).

One case was of the movement of the Pointer Device toward the vertex of the side panels, whereas the second case corresponded to what she called the movement "backward". Out of a boundless complex realm of possibilities in which discrete cases can be sorted out in infinite ways, Carlene articulated two of them corresponding to the tracing of sides ' 1 ' and ' 3 ' of the triangle. Note that Carlene developed these cases not in terms of empirical possibilities, which would result from utterances of the sort "when I move the laser pointer device toward the vertex, I notice that the two lights move toward each other", but in terms of logical necessity (i.e. the two lights must move toward each other when the device approaches the vertex).

What was the ground of such logical necessity? We will highlight two aspects that partially address this question:

1. The two cases were disjoint, non-overlapping. The possibility of a motion that would fall onto both of them seemed excluded. Carlene achieved this by choosing hand motions to illustrate each case that brought in a sense of opposition, along the lines of a forward/backward dichotomy.

2. Each case invoked a background of life experience of space-time relationships, within which the lights moving toward each other (forward motion) or not (backward motion), appeared obvious and evident. This obviousness reflects countless and radical constraints on what the possibilities are; such constraints do not need to be made explicit because they stem from comprehensive backgrounds of life experience. Given the spatial configuration attributed to the laser pointer, its surrounding implicit constraints (e.g. it moves on a flat surface, the laser lights do not bend, the side panels are straight, each light is perpendicular to a side panel, etc.), and the familiarity of

Fig. 12 Juxtaposing displacements in Utterances $1-3$

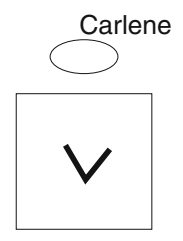

U1

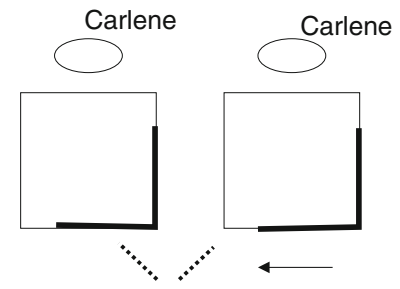

U2

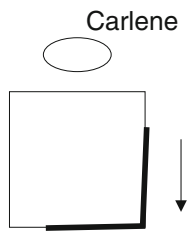

U3

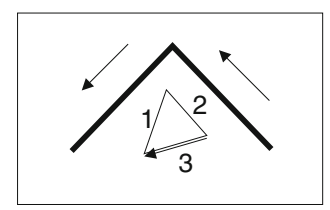




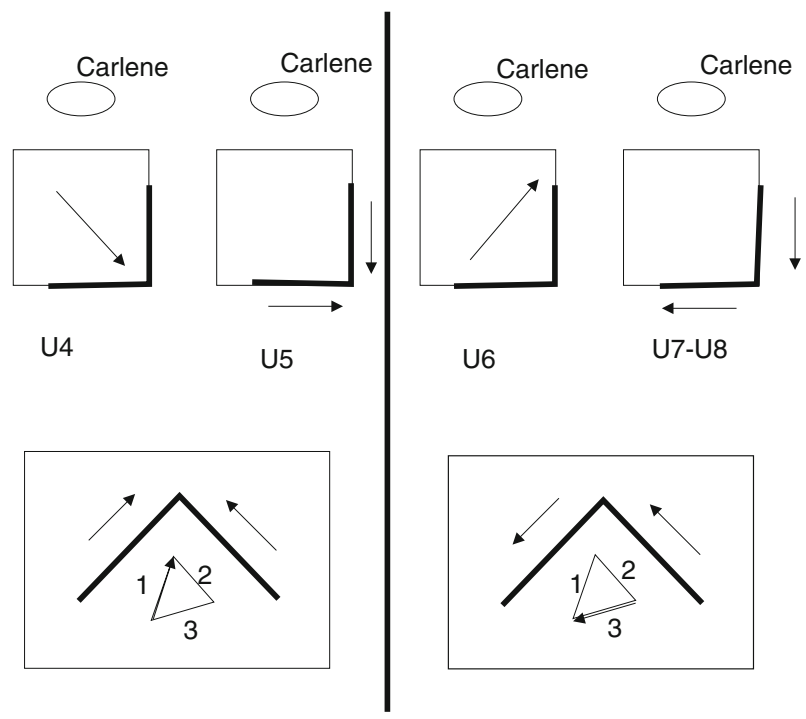

Fig. 13 Articulating two necessary cases in Utterances 4-8

certain relevant relationships (e.g. perpendicularity, simultaneity, linearity, flatness, etc.) it came to be apparent that it was impossible for the laser lights to do otherwise. Carlene achieved this appearance by illustrating each case in terms of familiar and pervasive spatio-temporal relationships.

In Section 3 we suggested the notion of "thought" as an interpretation of one or more utterances. We can use the present example to clarify this idea. What were Carlene's thoughts that she expressed through her utterances? The most succinct description of her thoughts was produced by Mr. Barros in Utterance 9: "Oh, OK. So one time they go in the same direction. And another time they go in the opposite direction". However, we avoid reifying thoughts as entities with causal powers that manifest themselves in contingent and contextualized utterances. What is actually experienced and felt are the utterances themselves, with their overt and covert aspects, each of them embedded in a "just past" (its origin) and an "about to happen" (its future-oriented aim). In our example, Carlene's thoughts are interpretations of her utterances oriented to grasping their unity or overall "point". Like all interpretations, they are open-ended descriptions that reflect a certain "take" on the interpreted phenomena. Mr. Barros' interpretation was his way of making sense of Carlene's utterances - an interpretation that coincided with Carlene's own, as she indicated through her animated approval. At another moment Mr. Barros, Carlene, Tracy, or any of the other students, might offer a complementary or alternative account for her thoughts. There is not an ultimate thought to be ascertained. By re-contextualizing Carlene's utterances, the question of what she thought remains open.

Note that we described Utterance 9 as a combination of Carlene's gestures and Mr. Barros' words. It was a joint utterance. We propose this notion of joint utterances as a crucial aspect of social interaction. To understand how such cooperative uttering is achieved, we find helpful the perspective that Gallese $(2003,2007)$ has developed on empathy and intersubjectivity, centered on the action of the "mirror systems". The mirror systems are neurological means that allow for partial overlap between perceiving 
someone else performing a goal-oriented action and enacting that action oneself, the latter being usually enacted in covert ways. They make plausible the idea that one grasps someone else's utterance by partially enacting that same utterance in oneself. Gallese contrasts this idea with the traditional assumption that we develop such interpersonal understanding exclusively through inferential reasoning. The contention is that the mirror systems allow us to develop empathetic and mutual understanding in a direct fashion, out of the actual production, in first person, of the utterances one perceives in others. This framework suggests that Carlene's nine utterances were not restricted to her own imaginary activity. Like someone orchestrating collective phenomena, Carlene's utterances guided the imaginary activity of the teacher and of the classmates attentive to her, establishing a field of intersubjectivity from which others could develop interpretations for what she thought.

Broadening the scope of embodied cognition toward encompassing the imaginary helps us to shift our attention from "what is" to "what could be". "What is" seems the natural orientation of perceptuo-motor activity. Imagining brings up empirical or pure possibilities (i.e. "what could be") shaping the course of perceptuo-motor activity, and therefore it is particularly essential to account for the experience of abstract realms, such as mathematics. Viewing mathematics learning as an enrichment of mathematical imagination can illuminate the roles of tools and materials - not as "embodiments" of mathematical ideas, but as means to productively extend the horizon of possibilities that students come to entertain.

Acknowledgments This research has been supported by the Math in Motion project (NSF REC0087573). Opinions expressed are those of the authors and not necessarily those of the Foundation. We would like to thank the students in Mr. Barros's class for all that they have taught us. We would also like to thank the members of the "Math in Motion" group, Djalita Oliveira-Ramos for her help in translating and analyzing the data for this paper, and Laurie Edwards for her feedback on a previous version. We extend our acknowledgements to three anonymous reviewers and Luis Radford for their invaluable feedback

\section{References}

Arzarello, F. (2006). Semiosis as a multimodal process. Revista Latinoamericana de Investigación en Matemática Educativa, 9 (Special issue on semiotics, culture and mathematical thinking), 267-299.

Casey, E. (1979). Imagining. Bloomington: Indiana University Press.

Erickson, F. (2004). Talk and social theory. Cambridge, UK: Polity Press.

Ferrara, F. (2006). Remembering and Imagining: Moving back and forth between motion and its representation. In J. Novotná, H. Moraová, M. Krátká \& N. Stehlíková (Eds.) Proceedings of the Thirtieth Conference of the International Group for the Psychology of Mathematics Education, (vol. 3, pp. 65-72). Prague: Charles University

Gallese, V. (2003). The roots of empathy: The shared manifold hypothesis and the neural basis of intersubjectivity. Psychopathology, 36(4), 171-180. doi:10.1159/000072786.

Gallese, V. (2007). Before and below 'theory of mind': Embodied simulation and the neural correlates of social cognition. Philosophical Transactions of the Royal Society B, 362(1480), 659-669. doi:10.1098/ rstb.2006.2002.

Gallese, V., \& Lakoff, G. (2005). The brain's concepts: The role of the sensory-motor system in conceptual knowledge. Cognitive Neuropsychology, 22(3-4), 455-479. doi:10.1080/02643290442000310.

Husserl, E. (1983). Ideas pertaining to a pure phenomenology and to a phenomenological philosophy-First Book (R. Rojcewicz \& A. Schuwer, Trans.). The Hague: Martinus Nijhoff Publishers.

Hutchins, E. (2005). Material anchors for conceptual blends. Journal of Pragmatics, 37(10), 1555-1577. doi:10.1016/j.pragma.2004.06.008. 
Johnson, M. (1987). The body in the mind: The bodily basis of meaning, imagination, and reason. Chicago: University of Chicago Press.

Lakoff, G., \& Núñez, R. E. (2000). Where mathematics comes from: How the embodied mind brings mathematics into being. New York: Basic Books.

Noble, T. (2007). Body Motion and Physics: How elementary school students use gesture and action to make sense of the physical world. Unpublished Doctoral Dissertation, Tufts University, Medford, MA.

Radford, L. (2006). Elements of a cultural theory of objectification. Revista Latinoamericana de Investigación en Matemática Educativa, 9 (Special Issue on Semiotics, Culture and Mathematical Thinking), 103-129.

Radford, L., Bardini, C., Sabena, C., Diallo, P., \& Simbagoye, A. (2005). On embodiment, artifacts, and signs: A semiotic-cultural perspective on mathematical thinking. In H. L. Chick \& J. L. Vincent (Eds.), Proceedings of the 29th International Group for the Psychology of Mathematics Education (vol. 4, pp. 113-122). Melbourne, Australia.

Robutti, O. (2006). Motion, technology, gesture in interpreting graphs. International Journal of Computer Algebra in Mathematics Education, 13, 117-126.

Roth, W.-M., \& Welzel, M. (2001). From activity to gestures and scientific language. Journal of Research in Science Teaching, 38(1), 103-136. doi:10.1002/1098-2736(200101)38:1<103::AID-TEA6>3.0.CO;2-G.

Sabena, C. (2007). Body and signs: A multimodal semiotic approach to teaching-learning processes in early calculus. Unpublished Doctoral Dissertation, Università degli Studi di Torino, Torino.

Vygotsky, L. S. (1986). Thought and language. Cambridge, MA: MIT Press. 